\title{
Volar Dislocation of the Fourth and Fifth Carpometacarpal Joints: A Case Report and Review of the Literature
}

\author{
Peter M. Prokopis, MD • Andrew J. Weiland, MD
}

Received: 13 June 2008/Accepted: 13 June 2008/Published online: 31 July 2008

(C) Hospital for Special Surgery 2008

\begin{abstract}
We report the treatment of a volar dislocation to the fourth and fifth carpometacarpal (CMC) joints. Plain radiographs were used to evaluate this unusual injury before surgery. Open reduction and internal fixation using K-wires restored the normal anatomic relationships of the $\mathrm{CMC}$ joints. This very rare injury is often difficult to recognize. A careful neurologic assessment of the patient is a necessity, as well as obtaining proper radiographs of the hand. A review of the literature is presented.
\end{abstract}

\section{Introduction}

Carpometacarpal (CMC) dislocations are injuries created by a direct high-energy blow to the hand. The volar or dorsal displacement of the metacarpals is determined by the direction of the force applied to the hand at the time of injury [1]. Volar CMC dislocations are a rare injury. McWhorter first described a volar CMC dislocation in 1918 [2]. In 1968, Nalebuff described volar-radial and volar-ulnar fifth CMC dislocations [3]. In the volar-radial type, all of the ligamentous and tendonous structures are disrupted resulting in marked displacement of the metacarpal base. In the volar-ulnar type, the pisometacarpal ligament remains intact, thereby preventing excessive displacement of the fifth metacarpal base.

There have been sporadic case reports of volar $\mathrm{CMC}$ dislocations in the literature [4-28]. While there are reports of treating these rare injuries with closed reduction and casting $[4,5,20,28]$, open reduction and internal fixation is

P. M. Prokopis, MD.A. J. Weiland, MD ( $₫)$

Department of Hand and Upper Extremity Surgery,

The Hospital for Special Surgery, New York, NY, USA

e-mail: weilanda@hss.edu

P. M. Prokopis, MD

Sports Medicine North,

One Orthopedics Drive, Peabody, MA 01960, USA usually required to stabilize the injury. Failure to diagnose these injuries or inability to maintain an anatomic reduction will predispose the patient to pain as well as grip weakness $[15,29]$.

The purpose of this report is to present a case of this very rare injury. A careful neurologic and radiographic assessment of the patient is imperative. Operative treatment is usually required to reduce and maintain an anatomic reduction. A review of the literature is also presented.

\section{Case report}

A 65-year-old right-hand-dominant male sustained an injury to his right hand. He fell while crossing the street onto his outstretched hand. He noticed immediate pain and deformity of his hand. One day after injury, he presented to the senior author (AJW) complaining of pain, swelling, and persistent deformity. Physical examination demonstrated marked splaying of the long and ring fingers, as well as significant swelling (Figs. 1 and 2). There was a palpable prominence in the volar hypothenar region. Subjectively, sensation was intact in the median and ulnar nerve distributions, as well as intact abductor pollicis brevis, flexor pollicis brevis, and interossei function. Anteroposterior and lateral radiographs demonstrated volar-ulnar dislocations of the fourth and fifth CMC joints (Figs. 3 and 4). Oblique and $30^{\circ}$ pronated lateral views were also obtained.

The following day, under regional anesthesia, closed reduction was attempted. The volar dislocation was reduced manually, but there was persistent ulnar subluxation of the fourth and fifth $\mathrm{CMC}$ joints visible on intraoperative fluoroscopic views. At this point, open reduction was performed through a transverse incision over the fourth and fifth $\mathrm{CMC}$ joints. Internal fixation was achieved using three $0.045 \mathrm{~K}$-wires. Anatomic reduction of the CMC articulations was obtained (Figs. 5 and 6). The patient was immobilized in a volar splint. 


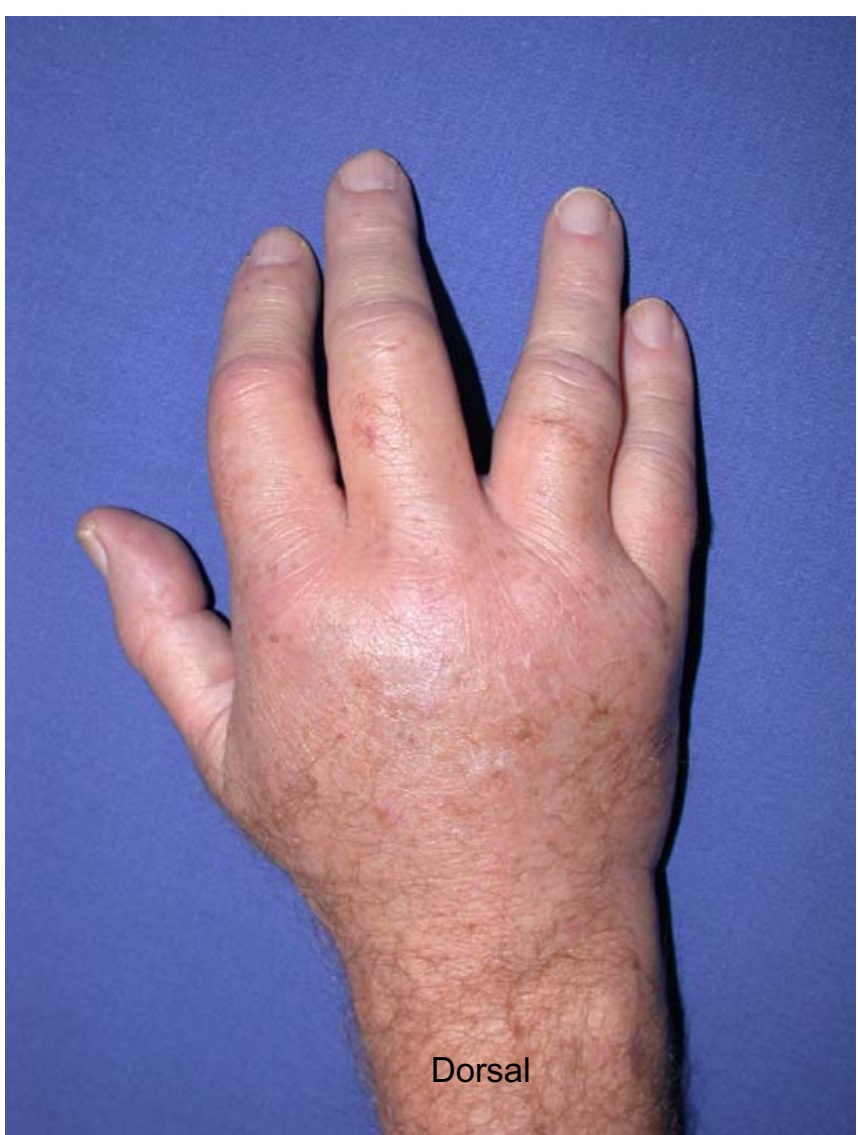

Fig. 1. Preoperative dorsal clinical photo demonstrating significant swelling as well as splaying of the long and ring fingers

At 6 weeks postoperatively, the K-wires were removed and hand therapy was initiated. Three months postoperatively, the patient had full painless active range of motion equal to his contralateral side (Figs. 7 and 8). Grip strength was also equal bilaterally. Radiographs demonstrated maintenance of reduction (Figs. 9 and 10).

\section{Discussion}

CMC dislocations to the hand, whether dorsal or volar, can have severe consequences if not identified and treated adequately. Diligence in making the proper diagnosis is the first step in preventing a poor outcome. CMC dislocations are often missed in the emergency department even when reviewed by an orthopedic surgeon [30]. This can result in a delay in diagnosis from the time of injury from 2 days to 4 months.

In the acute state, the hand will often appear grossly swollen. In our patient, there was a very characteristic clinical appearance to the hand (Figs. 1 and 2). The classic description of this injury came from Waugh and Yancy [31]. They described the deformity of volar CMC dislocations as a "spade" type of deformity.

A careful neurologic evaluation must be performed. The deep motor branch of the ulnar nerve lies volar to the fifth
$\mathrm{CMC}$ joint as it courses around the hook of the hamate. It is vulnerable to injury in both dorsal $[32,33]$ and volar $[11$, 23] CMC dislocations. The median nerve has also been affected by volar CMC dislocations resulting in acute carpal tunnel syndrome [1].

Radiographic evaluation is a crucial step in making the diagnosis of a CMC dislocation. Interpretation of the radiographs should be performed by one who has a thorough knowledge of carpal anatomy [31]. Standard anteroposterior, lateral, and oblique views are a basic necessity. Dorsal or volar displacement may be visible on the lateral projection, but displacement is often obscured by superimposition of the central metacarpals [34]. Further evaluation of the fourth and fifth $\mathrm{CMC}$ joints can be performed using special radiographic views. Bora and Didizian described a view with the forearm pronated $30^{\circ}$ from the routine AP projection or supinated $60^{\circ}$ from the routine lateral projection to better study the fifth $\mathrm{CMC}$ joint [35]. The fifth $\mathrm{CMC}$ joint can also be projected in profile using a $30^{\circ}$ pronated lateral view [36, 37]. A special view for evaluating the second metacarpal base has also been described [21].

There are several reports of isolated volar fifth CMC dislocations $[2,3,5,6,8,10,16,20,22,27]$. While two of these cases were treated successfully with closed

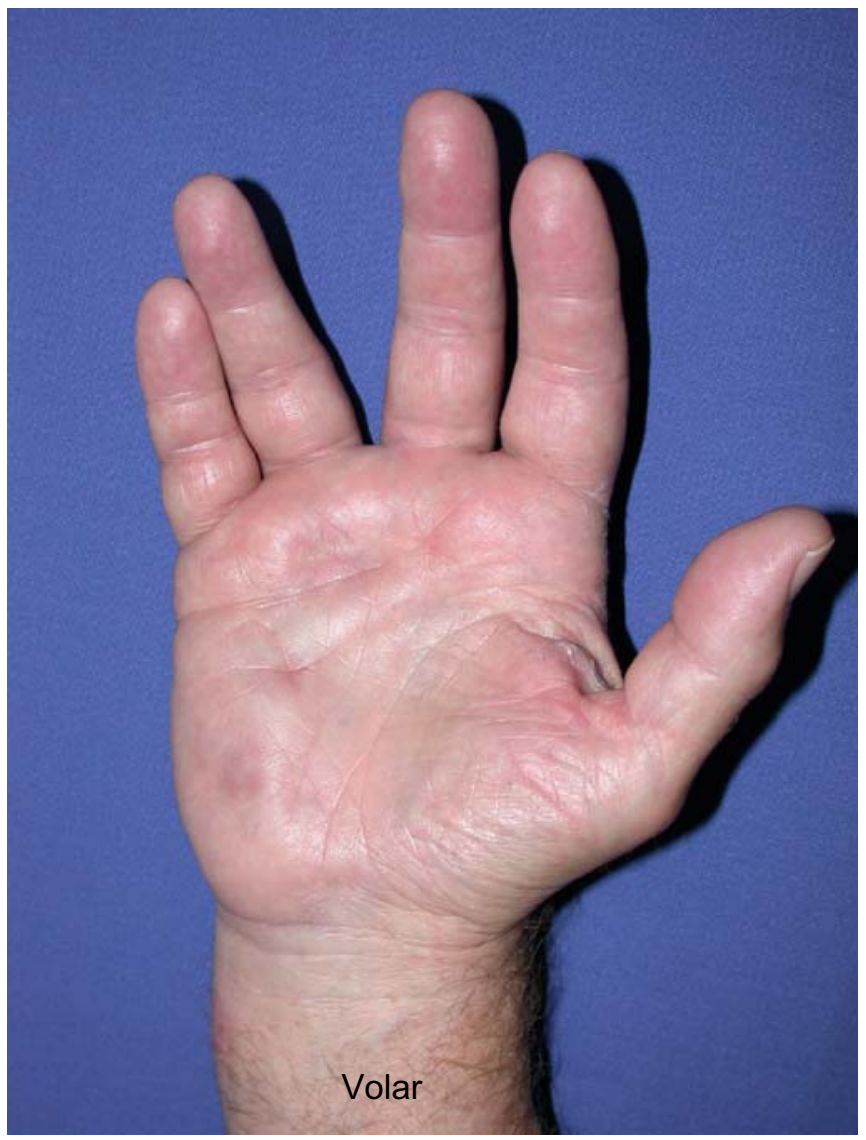

Fig. 2. Preoperative volar clinical photo demonstrating significant swelling as well as splaying of the long and ring fingers 


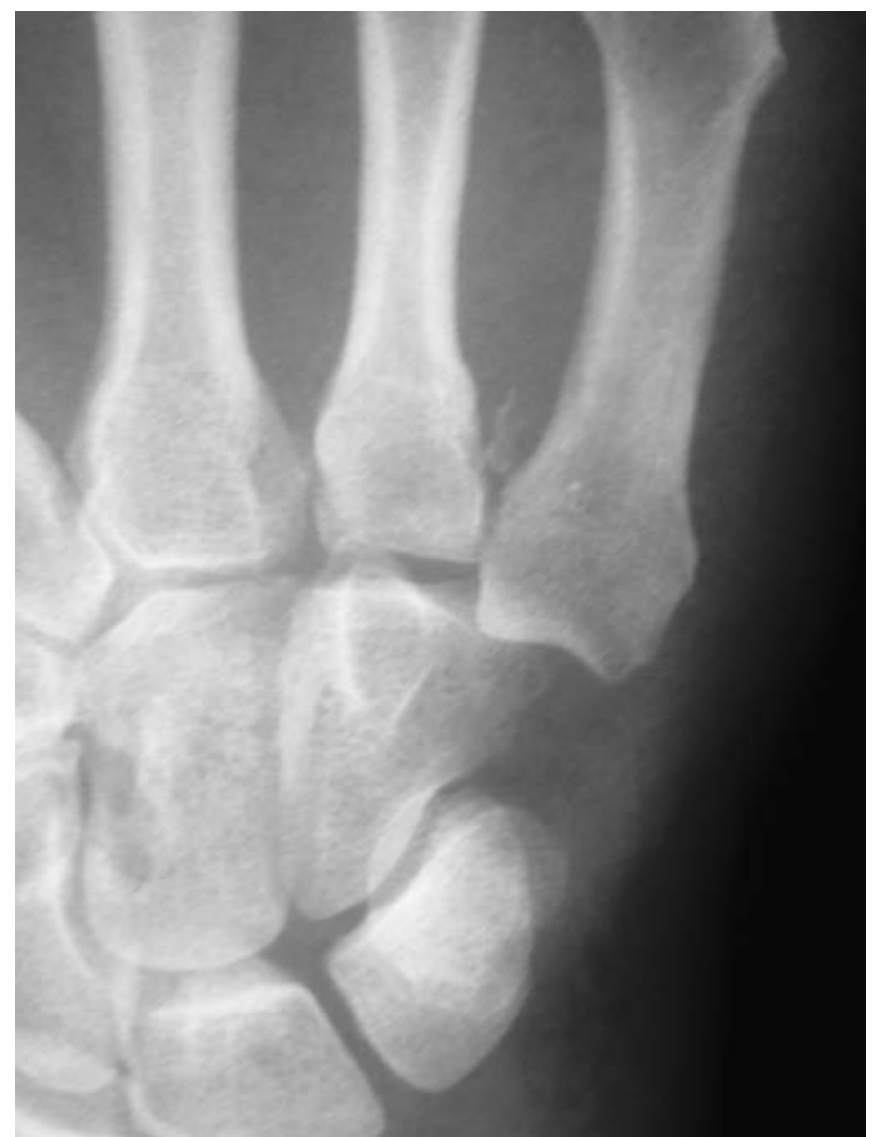

Fig. 3. Preoperative AP radiograph demonstrating proximal and ulnar displacement of the base of the fifth metacarpal on the hamate as well as an avulsion fracture off of the base of the fourth metacarpal

reduction and casting $[4,5,20,28]$, open reduction and internal fixation is usually necessary to achieve and maintain an anatomic reduction. There are two reports of isolated volar index finger CMC dislocations $[25,26]$, as well as two reports of volar CMC dislocations of the

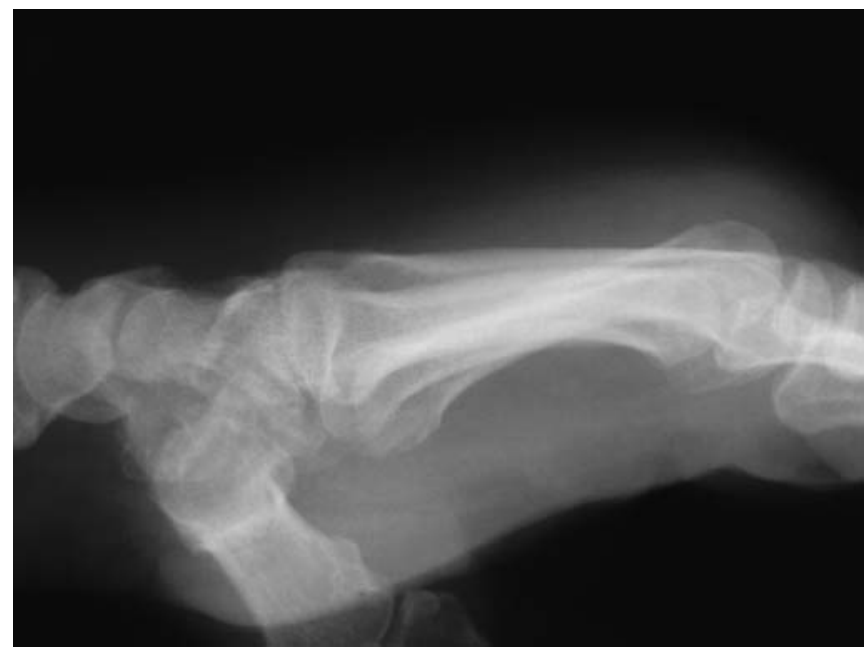

Fig. 4. Preoperative lateral radiograph demonstrating volar subluxation of the bases of the fourth and fifth metacarpals

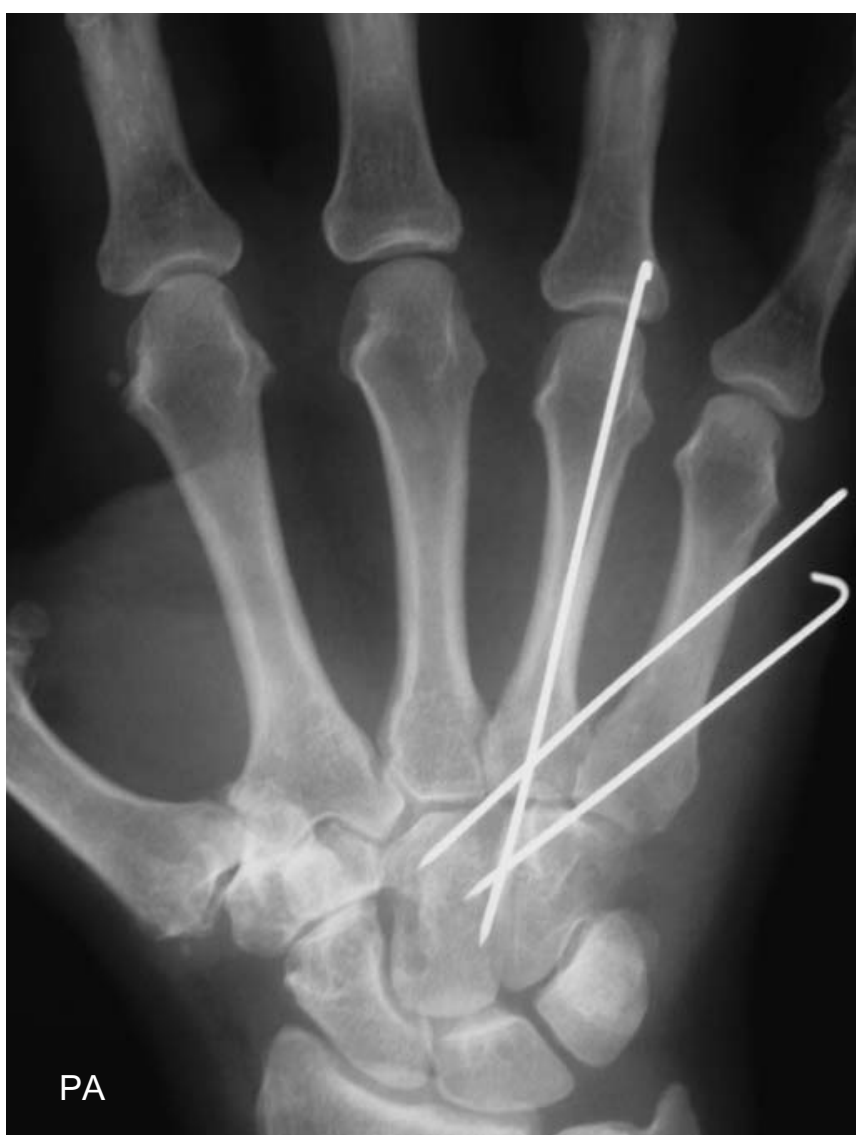

Fig. 5. Postoperative AP radiograph demonstrating anatomic restoration of the fourth and fifth CMC joints

index and long fingers $[1,14]$. Three authors report volar CMC dislocations of the four ulnar metacarpals $[4,17$, 19], while there is one report of divergent CMC volar dislocations between the second $\mathrm{CMC}$ and the three ulnar CMC joints [18].

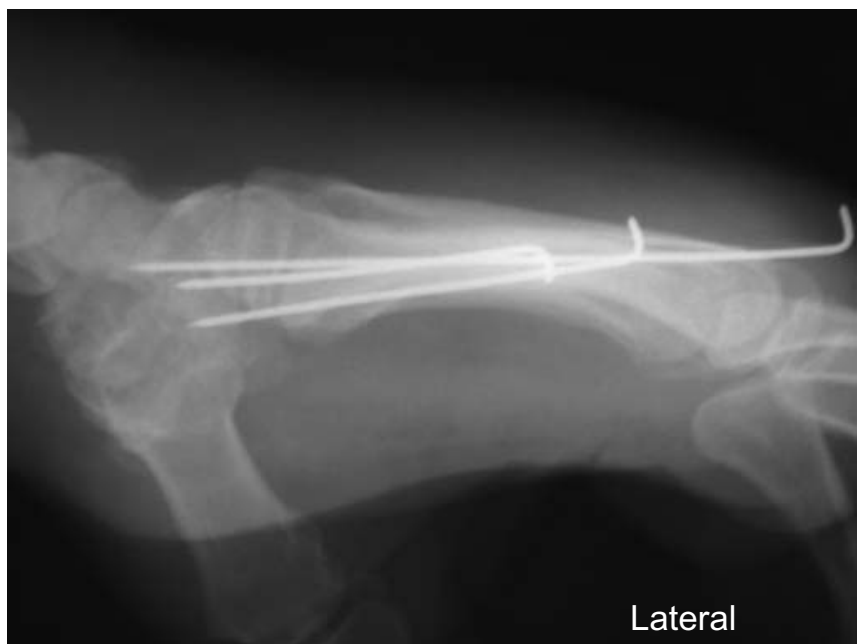

Fig. 6. Postoperative lateral radiograph demonstrating anatomic restoration of the fourth and fifth CMC joints 


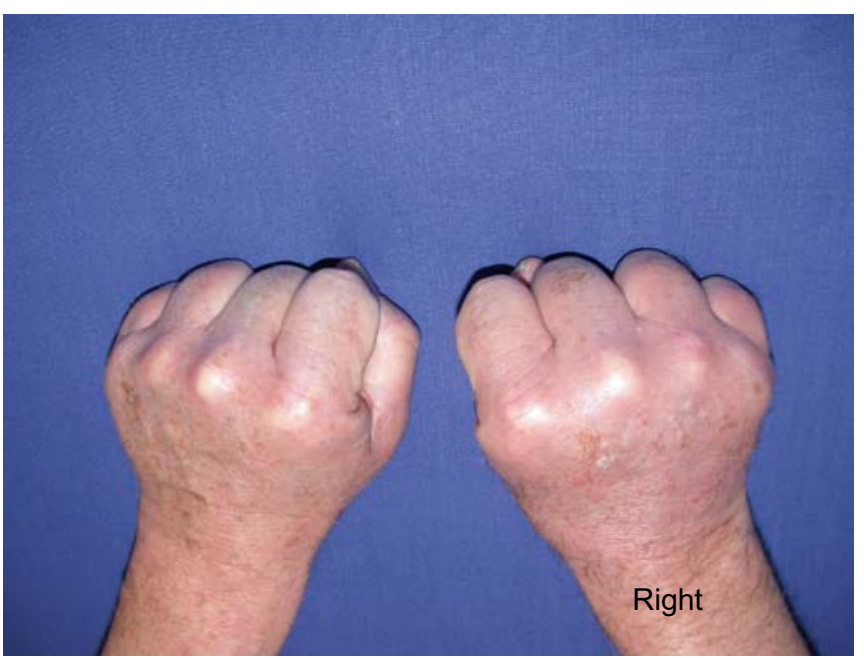

Fig. 7. Three months postoperative clinical photo demonstrating restoration of full hand motion on the injured side (right) compared to the contralateral (left) side

We report the rare case of isolated volar CMC dislocations of the ring and small fingers treated with open reduction and internal fixation. There are two cases in the English literature that include multiple CMC dislocations where the index and long finger metacarpals were displaced dorsally and the ring and small fingers volarly [12, 13]. Isolated ring and small finger volar dislocations appear rarely. Careful analysis of radiographs as well as physical exam findings can ensure that this rare injury is not missed. Open reduction and internal fixation provides an excellent way to accurately and anatomically reduce and stabilize these rare injuries.

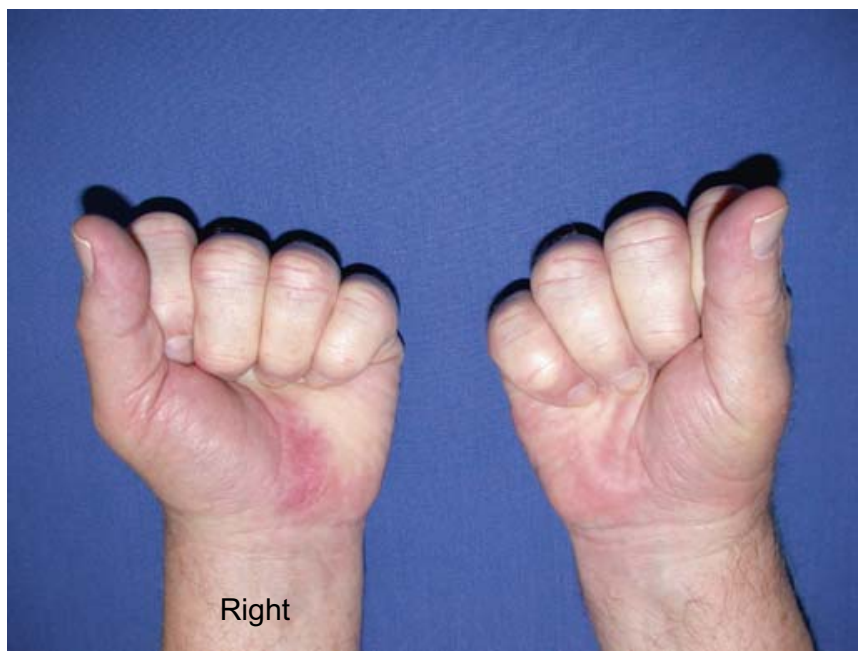

Fig. 8. Three months postoperative clinical photo demonstrating restoration of full hand motion on the injured side (right) compared to the contralateral (left) side

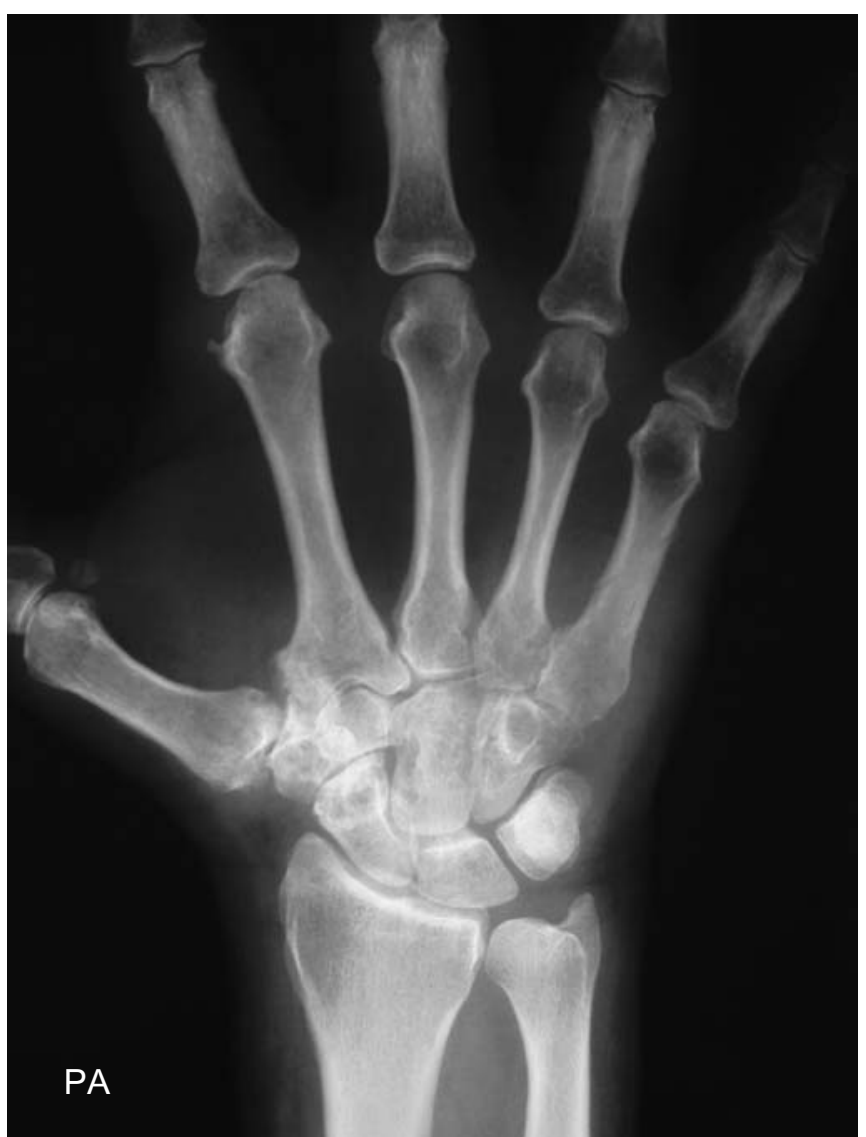

Fig. 9. Three months postoperative AP radiograph demonstrating maintenance of reduction of the fourth and fifth CMC joints

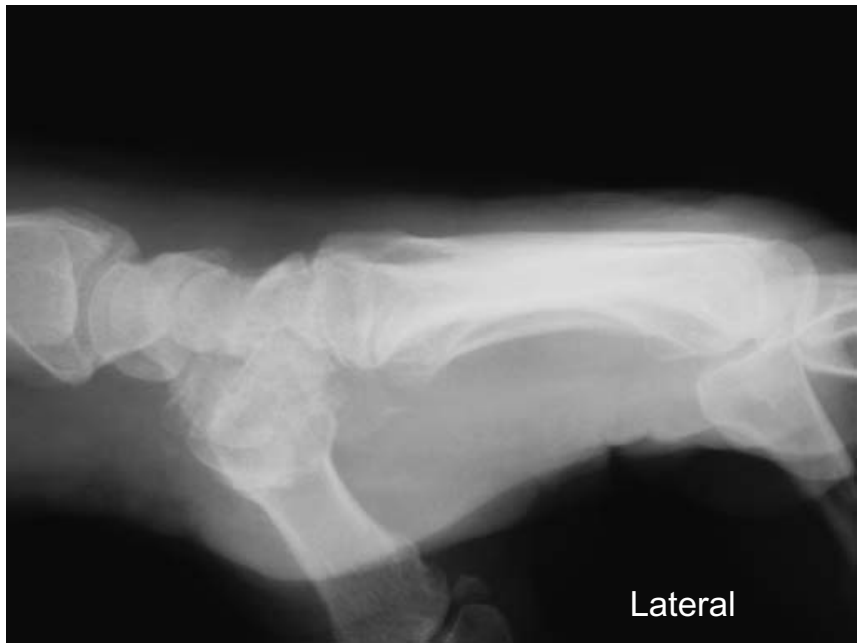

Fig. 10. Three months postoperative lateral radiograph demonstrating maintenance of reduction of the fourth and fifth CMC joints 


\section{References}

1. Weiland AJ, Lister GD, Villareal-Rios A (1976) Volar fracture dislocations of the second and third carpometacarpal joints associated with acute carpal tunnel syndrome. J Trauma 16:672-675

2. McWhorter GL (1918) Isolated and complete dislocation of the fifth carpometacarpal joint: open operation. Surg Clin Chicago 2:793-796

3. Nalebuff EA (1968) Isolated anterior carpometacarpal dislocation of the fifth finger: classification and case report. J Trauma 8:11191123 doi:10.1097/00005373-196811000-00017

4. Bajekal RA, Kotwal PP, Menon D (1992) Closed volar dislocations of the four ulnar carpometacarpal joints. Injury 23:355356 doi:10.1016/0020-1383(92)90197-Z

5. Berg EE, Murphy DF (1986) Ulnopalmar dislocation of the fifth carpometacarpal joint-successful closed reduction: review of the literature and anatomic reevaluation. J Hand Surg 11A:521-525

6. Buzby BF (1934) Palmar carpo-metacarpal dislocation of the fifth metacarpal. Ann Surg 100:555-557 doi:10.1097/00000658193409000-00022

7. Chen VT (1987) Dislocation of carpometacarpal joint of the little finger. J Hand Surg 12B:260-263

8. Dennyson WG, Stother IG (1976) Carpometacarpal dislocation of the little finger. Hand 8:161-164 doi:10.1016/0072968X(76)90040-1

9. Fernyhough J, Trumble T (1990) Late posttraumatic carpometacarpal dislocation of the ring and little finger. J Orthop Trauma 4:200-203 doi:10.1097/00005131-199004020-00019

10. Fischer JW, Waseem M, Gambhir A, Creedon RJ (2002) Ulnopalmar dislocation of the fifth carpometacarpal joint: a rare injury. Acta Orthop Belg 68:175-177

11. Gore DR (1971) Carpometacarpal dislocation producing compression of the deep branch of the ulnar nerve. J Bone Jt Surg 53A: $1387-1390$

12. Gunther SF, Bruno PD (1985) Divergent dislocation of the carpometacarpal joint: a case report. J Hand Surg 10A:197-201

13. Hartwig RH, Louis DS (1979) Multiple carpometacarpal dislocations: a review of four cases. J Bone Jt Surg 61A:906-908

14. Harwin SF, Fox JM, Sedlin ED (1975) Volar dislocation of the bases of the second and third metacarpals. J Bone Jt Surg 57A:849-851

15. Hazlett JW (1968) Carpometacarpal dislocations other than the thumb: a report of eleven cases. Can J Surg 11:315-323

16. Ker HR (1955) Dislocation of the fifth carpo-metacarpal joint. J Bone Jt Surg 37B:254-256

17. Kleinman WB, Grantham SA (1978) Multiple volar carpometacarpal joint dislocation: case report of traumatic volar dislocation of the medial four carpometacarpal joints in a child and review of the literature. J Hand Surg 3A:377-382

18. Kumar R, Malhoutra R (2001) Divergent fracture-dislocation of the second carpometacarpal joint and the three ulnar carpometacarpal joints. J Hand Surg 26A:123-129
19. Kumar S, Arora A, Jain AK, Agarwal A (1998) Volar dislocation of multiple carpometacarpal joints: report of four cases. J Orthop Trauma 12:523-526 doi:10.1097/00005131-199809000-00019

20. Lintner SA, Rettig AC (1995) Isolated volar carpometacarpal dislocation of the fifth digit. Am J Orthop 24:918-919

21. Mehara AK, Bhan S (1993) Rotatory dislocation of the second carpometacarpal joint: case report. J Trauma 34:464-466 doi:10.1097/00005373-199303000-00032

22. North ER, Eaton RG (1980) Volar dislocation of the fifth metacarpal: report of two cases. J Bone Jt Surg 62A:657-659

23. O'Rourke PJ, Quinlan W (1993) Fracture dislocation of the fifth metacarpal resulting in compression of the deep branch of the ulnar nerve. J Hand Surg 18B:190-191

24. Roberts N, Holland CT (1936) Isolated dislocation of the base of the fifth metacarpal. Br J Surg 23:567-571 doi:10.1002/ bjs. 1800239110

25. Schutt RC, Boswick JA, Scott FA (1981) Volar fracturedislocation of the carpometacarpal joint of the index finger treated by delayed open reduction. J Trauma 21:986 doi:10.1097/ 00005373-198111000-00015

26. Thomas WO, Gottliebson WM, D’Amore TF, Parry SW (1994) Isolated palmar displaced fracture of the base of the index metacarpal: a case report. J Hand Surg 19A:455-456

27. Tountas AA, Kwok JMK (1984) Isolated volar dislocation of the fifth carpometacarpal joint: a case report. Clin Ortop 187: $172-175$

28. Woo CC (1988) Traumatic volar dislocation of the second, third, and fourth carpometacarpal joints: mechanism and manipulation. J Manip Physiol Ther 11:124-129

29. Hsu JD, Curtis RM (1970) Carpometacarpal dislocations on the ulnar side of the hand. J Bone Jt Surg 52A:927-930

30. Henderson JJ, Arafa MAM (1987) Carpometacarpal dislocation: an easily missed diagnosis. J Bone Jt Surg 69B:212-214

31. Waugh RL, Yancey AG (1948) Carpometacarpal dislocations. J Bone Jt Surg 30A:397-404

32. Peterson P, Sacks S (1986) Fracture-dislocation of the base of the fifth metacarpal associated with injury to the deep motor branch of the ulnar nerve: a case report. J Hand Surg 11A:525-528

33. Young TB (1987) Dorsal dislocation of the metacarpal base of the little and ring fingers with ulnar nerve compression. Injury 18:6573 doi:10.1016/0020-1383(87)90392-5

34. Glickel SZ, Barron OA, Eaton RG (1999) Dislocations and ligament injuries in the digits. In: Green DP (ed) Operative hand surgery, 4th edn. Churchill Livingstone, New York, p 786

35. Bora FW, Didizian NH (1974) The treatment of injuries to the carpometacarpal joint of the little finger. J Bone Jt Surg 56A: $1459-1463$

36. Fisher MR, Rogers LF, Hendrix RW (1983) Systematic approach to identifying fourth and fifth carpometacarpal joint dislocations. Am J Roentgenol 140:319-324

37. Fisher MR, Rogers LF, Hendrix RW, Gilula LA (1984) Carpometacarpal dislocations. Crit Rev Diagn Imaging 22: 95-126 